\title{
A Tradução Da Morte De Khadafi
}

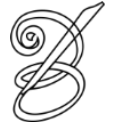 \\ Fernanda M. Alves Lourenço \\ (Mestranda - UFSC) \\ feerfl@ hotmail.com \\ Tahne Bohrer Martins \\ (Pós-Graduanda - PUCRS) \\ tahnemartins@hotmail.com
}

\begin{abstract}
Resumo: A questão de o jornalista desempenhar, também, o papel de tradutor dos fatos noticiosos não é algo que muitos profissionais do meio jornalístico consideram; porém, Zipser (2002), através de sua pesquisa, constatou que realmente existe essa interface tradução-jornalismo. Nesse sentido, este artigo tem por objetivo demonstrar, por meio de duas reportagens, uma pertencente à BBC UK e a outra à BBC Brasil, como tal relação ocorre. Primeiramente, escolheu-se reportagens pertencentes ao mesmo meio de comunicação, no caso jornal online, e que noticiassem o mesmo acontecimento - a primeira notícia da morte de Khadafi. Em seguida, com base nos trabalhos de Nord (1991) sobre o funcionalismo na tradução e de Zipser (2002), fizemos as análises das reportagens. Assim, foi possível verificar como a "representação cultural" (Zipser, 2002) e o público leitor influenciaram na forma de redação da mesma notícia em países distintos, levando em consideração o jornalistatradutor.
\end{abstract}

Palavras -chave: Tradução, Jornalismo, Cultura, Reportagem.

Abstract: The issue of a Journalist also playing the role of a Translator of facts is not something taken into consideration by many professionals in the journalistic area. However, Zipser (2002) has shown, through academic research, that the translation-journalism interface actually exists. Therefore, this paper aims to demonstrate how this relationship occurs by analyzing two news reports: one from BBC UK and the other from $B B C$ Brazil. Firstly, we selected reports about the same fact - the death of Gaddaf - from the same media source, in this case an online newspaper. Then, based on Nord's (1991) work on functionalism in translation and the interface translation-journalism in Zipser (2002) we analyzed the reports. The analysis showed how the "cultural representation", according to Zipser (2002), and the public reader have both influenced the writing of a single fact in different countries, taking into account the journalist acting as a translator.

Keywords: Translation, Journalism, Culture, News facts.

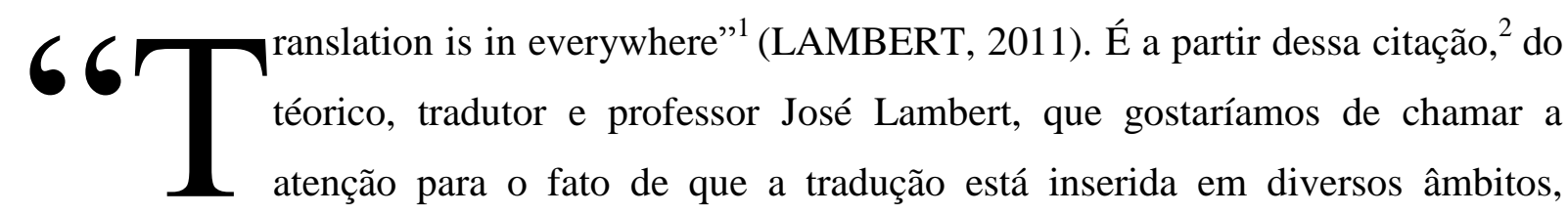
conforme já apresentado pelos Estudos Descritivos da Tradução, os quais visam “demonstrar que a teoria da tradução não se deve limitar a ser um ramo da linguística, mas pode até complementá-la, em muitos aspectos”. (ROMANELLI, 2006, p. 83).

Dessa forma, a tradução também pode estar inserida em outras áreas afins (sociologia, psicanálise, etc.), "gerando interfaces de investigação e conduzindo a tradutologia a uma característica multidisciplinar" (POLCHLOPEK, 2011, p. 17). 
Proposta por Zipser (2002), a relação tradução-jornalismo é um dos âmbitos que vem ganhando seu lugar dentro das pesquisas acadêmicas. Muitos jornalistas não consideram que a tradução seja algo que faça parte de seu objeto de trabalho e é justamente o contrário que essa interface quer suscitar.

A autora relata que

\begin{abstract}
a tradução do texto-fonte que noticia o fato, realizada segundo critérios de fidelidade ao texto e à cultura de partida, não constitui necessariamente um texto jornalístico. Mas ela pode existir e ser publicada como matéria assinada ou então servir de insumo, nas redações dos órgãos de imprensa, para a elaboração de um outro texto. Este outro texto, por sua vez, "traduz" o fato a ser noticiado, agora a partir da perspectiva da cultura que será destinatária da notícia. (ZIPSER, 2002, p. 13)
\end{abstract}

O leitor-destinatário e a cultura constituem o centro das atividades, tanto da teoria funcional da tradução quanto do jornalismo, pois a função do texto somente será realizada no momento em que ocorrer a conexão entre texto-destinatário, sendo algumas de suas funções as de informar, persuadir e formar opiniões (ZIPSER, 2002, p. 11-12).

Nesse sentido, o significado de tradução utilizado para este trabalho será o proposto por Eco (2007, p. 50), o qual afirma que a tradução, mais do que uma passagem entre duas línguas, é a passagem entre duas culturas ou duas enciclopédias. Ele também aponta que "o tradutor deve escolher a acepção ou o sentido mais provável e razoável e relevante naquele contexto e naquele mundo possível" (ECO, 2007, p. 50). Podemos afirmar que essa citação do autor se associa ao papel desempenhado pelo jornalista, o qual deve levar em consideração os aspectos mencionados ao produzir, isto é, ao "traduzir" a notícia.

Eco assinala que "um tradutor não deve levar em conta somente as regras estritamente linguísticas, mas também os elementos culturais no sentido mais amplo do termo" (ibidem, p. 190).

Corroborando a esse pensamento, citamos Zipser (2002, p. 19), a qual salienta que da mesma forma como a tradução não pode ser mais desvinculada da questão cultural, "também para o jornalismo não se pode pensar na 'tradução' de fatos sem a devida referência à cultura local".

A tradução sob uma perspectiva cultural, abordada tanto por Zipser (2002) quanto por Eco (2007), encontra-se presente também na Teoria Funcionalista da Tradução de Nord (1991). Zipser (2002, p. 48) aponta que "no funcionalismo de Nord a tradução é um processo (...) voltado para frente, para o destinatário que quer atingir", pois depende da função ou do skopos (finalidade) determinados pelas particularidades presentes na cultura de chegada 
(NORD, 1991).

Em relação ao jornalismo, temos a acepção dada por Melo (1994, apud PINHO, 2003) a respeito do conceito de jornalismo utilizado neste artigo, sendo possível perceber como ambas visam desenvolver textos que atendam às necessidades de cada contexto, ou seja, de cada cultura na qual está inserido. Logo, Melo (1994, apud PINHO, 2003, p. 56) relata que

\footnotetext{
o jornalismo é concebido como um processo social que se articula a partir da relação entre organizações formais e coletividades, através de canais de difusão [...] que asseguram a transmissão de informações em função de interesses e expectativas.
}

Atrelada a essa definição, apresentamos o conceito de "jornalismo digital" oferecido por Gonçalves (2000, apud PINHO, 2003, p. 58), que representa o objeto de estudo deste trabalho. O autor define o jornalismo digital como "todo produto discursivo que constrói a realidade por meio da singularidade dos eventos $[\ldots]$ ".

Além disso, ele aponta em seu trabalho algumas características peculiares ao jornalismo, as quais estão presentes também na tradução: clareza, concisão, precisão e coerência.

A partir desse panorama teórico, foram escolhidas duas reportagens on-line de uma mesma notícia, no caso, o primeiro anúncio da morte de Khadafi, sendo uma divulgada na BBC UK e outra na BBC Brasil. Nosso objetivo principal será o de seguir o caminho aberto por Zipser (2002) e analisar as perspectivas de enfoque culturais dadas a uma mesma reportagem em países distintos.

Propomo-nos ainda a verificar e discutir o processo tradutório existente no texto jornalístico brasileiro; mostrar a relação entre tradução e jornalismo presente nos textos a partir do modelo de Nord (1991), e assim tentarmos contribuir no preenchimento das lacunas ainda existentes nesse campo de estudo: tradução-jornalismo.

\section{TRADUÇÃO E CULTURA}

"A cultura é transmitida pela língua, sendo também seu resultado, o meio para operar e a condição da subsistência dessa cultura” (CARVALHO, 2010, p. 419). Portanto, pode-se partir do princípio de que a língua é por si só uma manifestação cultural. Escrever para um público, por meio da linguagem e da informação, é penetrar a cultura deste para lhe tocar, pois só assim uma mensagem será transmitida.

Diante disso, a tradução "exerce um poder enorme na construção de representações de culturas estrangeiras" (VENUTI, 2002, p. 130). O tradutor possui duplo papel cultural ao lidar com idiomas distintos: interpretar uma cultura e transmiti-la em outra. Eco (2007, p. 201) 
aponta que "é muito importante estudar a função que exerce uma tradução na cultura de chegada"; por isso, muito mais que conhecer o léxico, o tradutor deve estar a par do cenário cultural pertencente ao autor original.

Segundo Nicoloso (2010, p. 47), o tradutor é

visto como [...] um artista criativo que garante a sobrevivência da escrita através do tempo e do espaço, um mediador e intérprete intercultural, uma figura cuja importância para a permanência e difusão da cultura é inquestionável [...]

Atrelado a esse sentido, temos a visão funcionalista de Nord (1991), que trata a tradução como um processo intercultural do texto, ou seja, o tradutor deve levar em consideração o tempo, espaço e o cenário cultural, tanto do texto de partida quanto do texto de chegada.

Portanto, podemos considerar a tradução, mesmo que sutilmente, reveladora de valores, atitudes culturais e modos de expressão de uma época, em que o tradutor correrá o risco de não cumprir sua função caso aborde o texto isolado da cultura.

\section{FUNCIONALISMO}

Movimento linguista que iniciou em Praga por volta de 1926 que se difere das abordagens formalistas da linguagem pelo fato de considerar a língua uma ferramenta de interação social; busca no contexto discursivo a motivação para os fatos da língua, e considera a estrutura linguística como submetida às situações comunicativas, analisando, assim, toda a linguagem e estrutura gramatical de uma língua (MARTINS, 2009). Seu objetivo está no interesse de verificar como os usuários de uma língua a utilizam para se comunicar entre si de maneira eficiente.

Nessa visão funcionalista, em que cada indivíduo faz parte de um grupo social e usa a língua em situações variadas para atingir diferentes objetivos, o tradutor, ao traduzir a mensagem, precisa estar inteirado com a cultura do texto-fonte e a do texto-meta. $\mathrm{O}$ mesmo gerencia e realiza sua tarefa com os olhos voltados ao receptor, pois o leitor desse texto é o foco a ser atingido, já que a comunicação dar-se-á com ele (ZIPSER, 2002, p. 36).

Um modelo composto por fatores extratextuais e intratextuais foi proposto por Nord (1991), em que todas as características do texto são devidamente mapeadas e interrelacionadas, tanto para textos literários quanto para não literários, conforme poderá ser observado mais adiante (NORD, 1991, p. 5-6). 


\section{CONVERSANDO COM OS DADOS}

O corpus deste artigo se constitui de duas reportagens acerca da confirmação da morte de Khadafi divulgadas on-line nas BBC do Reino Unido e do Brasil.

O objeto de estudo foi escolhido devido a sua pertinência no mundo todo, bem como a representação cultural que envolve a tradução da notícia. Com respeito à $\mathrm{BBC}$ on-line sua escolha se deve ao fato desta representar um jornalismo sério e de destaque mundial.

Com o intuito de dar credibilidade e sustento a este trabalho, foram selecionadas somente reportagens de um único meio jornalístico (on-line) e que correspondessem à mesma notícia. Primeiramente será feita uma reflexão das diferenças e semelhanças dos textos e, em seguida, analisaremos as comparações e confrontos dos dados aferidos apoiados na teoria da tradução como "representação cultural" de fatos noticiosos (ZIPSER, 2002).

\section{AS REPORTAGENS: DA TRADUÇÃO PARA O TEXTO JORNALÍSTICO}

Inicialmente foram feitas as análises dos fatores internos e externos a partir do modelo de Nord (1991), o qual foi analisado com base no corpus deste trabalho. Segue abaixo:

\begin{tabular}{|c|c|c|}
\hline \multicolumn{3}{|c|}{ MODELO DE NORD } \\
\hline \multicolumn{3}{|c|}{ TEXTO 1 - "Libya's Col Muammar Gaddafi killed, says NTC" } \\
\hline \multicolumn{3}{|c|}{ TEXTO 2 - "Governo de transição anuncia morte de Khadafi" } \\
\hline & TEXTO-FONTE & TEXTO-META \\
\hline Emissor & BBC UK & BBC Brasil \\
\hline Intenção & $\begin{array}{l}\text { Informar a confirmação da morte } \\
\text { de Khadafi }\end{array}$ & $\begin{array}{l}\text { Informar a morte de Khadafi e os } \\
\text { efeitos desta }\end{array}$ \\
\hline Receptor & Público inglês & $\begin{array}{l}\text { Público brasileiro, leitor da BBC } \\
\text { no Brasil }\end{array}$ \\
\hline Meio & Jornal eletrônico & Jornal eletrônico \\
\hline Lugar & Reino Unido & Brasil \\
\hline Tempo & 2011 & 2011 \\
\hline Propósito & $\begin{array}{l}\text { Confirmar e detalhar a morte de } \\
\text { Khadafi ao Reino Unido }\end{array}$ & $\begin{array}{l}\text { Provocar o conhecimento e o } \\
\text { interesse pela notícia nos leitores } \\
\text { brasileiros }\end{array}$ \\
\hline Função textual & Referencial & Referencial \\
\hline \multicolumn{3}{|c|}{ FATORES INTERNOS AO TEXTO } \\
\hline Tema & Morte de Khadafi & Anúncio da morte \\
\hline Conteúdo & $\begin{array}{l}\text { Confirmação e detalhamento da } \\
\text { morte }\end{array}$ & $\begin{array}{l}\text { Confirmação, importância, } \\
\text { efeitos e detalhamento da morte }\end{array}$ \\
\hline Pressuposições & $\begin{array}{l}\text { Conhecimento prévio do povo } \\
\text { britânico em relação a situação } \\
\text { política da Líbia }\end{array}$ & $\begin{array}{l}\text { Falta de conhecimento do povo } \\
\text { brasileiro em relação à à } \\
\text { importância da notícia e àa } \\
\text { situação política da Líbia }\end{array}$ \\
\hline Estruturação & Lide/Vídeo amador com cenas & Lide/Vídeo introdutivo sobre a \\
\hline
\end{tabular}




\begin{tabular}{|c|c|c|}
\hline & 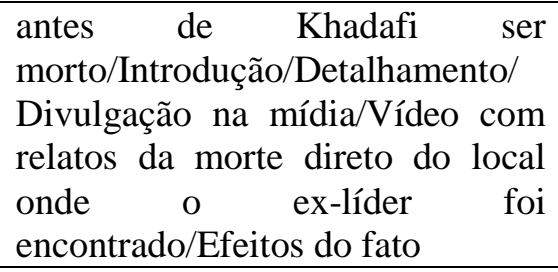 & 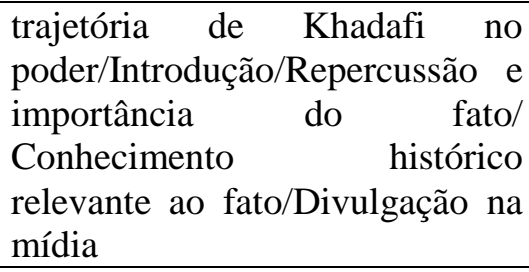 \\
\hline $\begin{array}{l}\text { Elementos } \\
\text { verbais }\end{array}$ & Vídeos e imagens & Vídeos e imagens \\
\hline Léxico & Texto jornalístico, informativo & Texto jornalístico, informativo \\
\hline Sintaxe & Simples & Simples \\
\hline Efeito do texto & $\begin{array}{l}\text { Informar, confirmar, detalhar e } \\
\text { comentar os efeitos sobre a morte }\end{array}$ & $\begin{array}{l}\text { Informar e relatar ao povo } \\
\text { brasileiro a morte e } \text { a } \\
\text { importância desse fato para a } \\
\text { Líbia. }\end{array}$ \\
\hline
\end{tabular}

Cumpre lembrar que em nenhuma das reportagens consta o nome dos editores;portanto, consideramos a citação de Bellos (2011, p. 243) que diz "Agency work does not seek to respect the original text or its origin, only facts that lie behind the narrative. The resulting wire is a collective composition and also a reduction or expansion attributable to no one individual, only to the service provider".

Em outras palavras, a agência on-line não tem o propósito de respeitar o texto original, nem mesmo quem o escreveu, apenas manter-se fiel aos fatos que o compõe. A notícia publicada é uma coleção de textos, com muitas atualizações, e não pode ser atribuída a um indivíduo em específico, somente à agência que o oferece. Logo, chegamos à conclusão de que os textos retratados passaram por diversos editores e redatores.

Percebe-se, de uma maneira geral, que não há uniformidade de layout nos textos, pois a reportagem brasileira é mais curta e apresenta menos vídeos do que a britânica. Quanto ao horário da última atualização da notícia, na BBC UK ela ocorreu às 21:02 GMT, ${ }^{3}$ já no Brasil foi às 17:31 GMT.

Partindo para o texto em si, a primeira diferença que pudemos constatar foi com relação ao título. Na reportagem da BBC Brasil, encontramos um título (lide) mais sucinto, relatando, apenas, que o governo de transição anunciou a morte de Khadafi, enquanto no título da BBC UK temos a apresentação dos dois primeiros nomes de Khadafi, de seu cargo na Líbia e da sigla NTC, ${ }^{4}$ que se refere ao governo de transição. Segue a transcrição dos dois títulos para uma melhor visualização: BBC Brasil - "Governo de transição anuncia a morte de Khadafi” e BBC UK - Libya's Col Muammar Gaddafi killed, says NTC.

Enquanto a BBC Brasil se preocupou em colocar, após o título, um vídeo narrativo com imagens que resgatavam a trajetória de mais de 40 anos do ex-líder opressor da Líbia, o 
Reino Unido publicou um breve vídeo amador narrado por uma correspondente de sua equipe que mostrava cenas de Khadafi antes de ser morto.

Como uma maneira de situar o leitor brasileiro em relação à qual seria o governo de transição citado no lide, é apresentado, no parágrafo que se segue após o vídeo, seu nome e sua sigla $\mathrm{CNT}^{5}{ }^{\mathrm{c}}$ com as devidas traduções para o português. Já no texto inglês, presumindo que seu leitor esteja situado dentro do contexto político da Líbia, é colocado apenas officials para se referir a quem anunciou a morte do ex-líder líbio.

Nesse primeiro tópico da reportagem é possível observar como o jornalismo brasileiro (JB), além de traduzir algumas partes do texto britânico, se preocupa em dar mais informações quanto à figura e o regime de Khadafi, ao passo que o jornalismo inglês (JI) se volta mais para a anunciação e o modo como ele morreu, apresentando, também, o depoimento de Barack Obama sobre a nova situação da Líbia, depoimento este que não foi citado no texto do Brasil. Presume-se que isso se dê pelo fato de o Reino Unido, assim como os EUA, também estar na luta pela libertação da Líbia.

No próximo tópico do JI: Golden gun, encontramos um texto relatando momentos e cenas em vídeos com detalhes da morte do ex-líder líbio. O texto aborda relatos que se diferem quanto ao membro Jibril da CTN e de seus combatentes. Seu subtítulo remonta exatamente à ideia de que a bala que atingira Khadafi era uma bala de ouro, tendo em vista que ela libertou o país.

O segundo tópico do JB intitulado "Confirmação" apresenta um texto destacando relatos de autoridades acerca da situação da Líbia frente a esse significativo acontecimento juntamente com o apontamento das características desse país.

Com relação ao último tópico da reportagem, encontramos no jornal inglês o subtítulo Full of challenges, que nos remete exatamente ao conteúdo exposto. Ele apresenta basicamente o que foi descrito pelo jornal brasileiro em seu segundo tópico, porém, com a diferença de ser um texto que se preocupa em dar mais ênfase à satisfação dos libaneses com a morte de seu opressor.

O texto é complementado com um vídeo feito por um de seus correspondentes no local onde Khadafi foi, supostamente, encontrado, ele narra tudo o que o acontecimento representa para o povo, mostrando imagens do seu contentamento.

Contudo, o jornal brasileiro inverteu as ordens do texto britânico e retratou em seu último tópico, de subtítulo "Imagens", vídeos e imagens feitas por programas de TV que atestam sobre a captura e morte do ex-líder da Líbia. 
Em síntese, o que pudemos constatar foi que a BBC britânica, por meio de um lide mais completo e subtítulos mais chamativos, preocupou-se em relatar um texto mais preciso, com muitos detalhes sobre a captura e morte, visto que foram colocados ao todo dois vídeos e um depoimento de sua correspondente, com relatos da morte de Khadafi e da alegria do povo líbio com esse fato. Além do mais, o texto é mais enriquecido de detalhes mórbidos, o qual apresenta uma ilustração do ex-líder morto e links que falam sobre a Líbia.

Já o jornalismo brasileiro da BBC, ao longo de seu texto, além de traduzir boa parte, também se preocupou em mostrar em quais circunstâncias ocorrera a morte de Khadafi e, sobretudo, situar seu leitor do verdadeiro significado desse acontecimento para a história da Líbia e de seu povo.

Para isso, ele fez o uso de um título e subtítulos simples e sucintos, de apenas um vídeo com a retrospectiva histórica do poder exercido pelo ex-líder, de uma foto do ex-líder líbio morto, a qual é diferente da exposta pelo JI, e também disponibiliza links que reportam o leitor à trajetória de Khadafi.

Assim, como forma de alegar nossa afirmação quanto ao texto brasileiro ser composto 136 em sua maioria por traduções do texto-fonte (BBC UK), foram extraídos das reportagens alguns exemplos:

1을 Exemplo

Texto-fonte: Libya's ex-leader Col Muammar Gaddafi has been killed after an assault on his birthplace of Sirte, officials say.

Texto-meta: "O ex-líder líbio Muamar Khadafi foi morto durante um ataque à sua cidade natal, Sirte, segundo o Conselho Nacional de Transição (CNT), que governa o país."

2을 Exemplo

Texto-fonte: Acting Prime Minister Mahmoud Jibril announced the death, and later said the colonel had been killed in a crossfire between Gaddafi loyalists and fighters from the transitional authorities. He confirmed that Col Gaddafi had been taken alive, but died of bullet wounds minutes before reaching hospital.

Texto-meta: "Nesta quinta-feira, horas depois do anúncio de que Khadafi teria sido capturado e levado a Misrata, o primeiro-ministro líbio Mahmoud Jibril confirmou sua morte para jornalistas." 


\section{$3^{\circ}$ Exemplo}

Texto-fonte: World leaders urged the NTC to carry through its promise to reform the country.

Texto-meta: "Líderes de diversos países comemoraram a notícia, pedindo que o CNT mantenha sua promessa de realizar reformas no país."

É possível notar nitidamente nesses exemplos como a cultura e o leitor-destinatário influenciaram na tradução brasileira, pois no primeiro exemplo, como já foi citado, ocorre a explicação da sigla do governo de transição, necessária para o entendimento do público brasileiro. No segundo, a reportagem inglesa é escrita de modo que o leitor imagine a cena da captura e, em seguida, apresenta uma informação extra que não está no texto em português, segundo o qual, ferido por balas, Khadafi teria morrido minutos antes de chegar ao hospital. Já o texto em português é mais explicativo quanto ao fato em si, isto é, sobre como ocorreu o anúncio de confirmação da morte para os jornalistas, e apresenta, inclusive, a data do ocorrido, se abstendo de mostrar detalhes da morte nesse trecho.

No terceiro exemplo há uma conotação mais fraca para a palavra urge (recomendar com insistência), pois o jornalismo brasileiro a traduziu simplesmente por "pedir", visto que a reforma do país foi mais do que um pedido, é algo que os líderes mundiais, como do Reino Unido, desejam e "cobram" da CNT.

Portanto, essa análise textual atesta exatamente o que expomos anteriormente, pois ficou claro que, embora pertencendo à mesma empresa de jornal on-line, as reportagens foram apresentadas para países com culturas diferentes, fato que fez com que o enfoque dado nas duas seguissem vieses distintos.

Constatou-se, ainda, que houve a função do jornalista como tradutor, não só como aquele que traduz a notícia ao leitor, mas o JB preocupou-se em levar a notícia para a cultura brasileira, com informações pertinentes para ambientar o leitor-destinatário, o qual não estava tão próximo e situado com a história da Líbia e de Khadafi como o leitor britânico.

O jornal britânico se mostrou em contato com o povo inglês ao comentar detalhes fortes da morte de Khadafi e também ao passar a veracidade dos dados que provavelmente satisfazem o povo inglês, transmitindo-lhe, quem sabe, segurança e até um certo alívio, conforme constatado no texto elaborado pelo jornalismo britânico. 
Portanto, a sociedade e a cultura foram levadas em consideração na produção das duas reportagens, demonstrando, assim, a representação cultural presente em cada texto e revelando o perfil jornalista-tradutor.

\section{CONCLUINDO: A REPRESENTAÇÃO CULTURAL E O LEITOR}

Neste trabalho, discutimos a relação entre tradução e cultura e a importância da presença desta em todos os âmbitos comunicacionais.

Mais uma vez, foi comprovada a interface tradução-jornalismo, a partir da análise das reportagens acerca da morte de Khadafi aqui apresentadas, pois, além de identificarmos como verdadeira a ideia do jornalismo como uma tradução de fatos, tendo em vista que se traduz aquilo que recebe em notícia, pudemos observá-lo também como um jornalista-tradutor formador de opinião.

Através do estudo das reportagens confirmamos que o fato é culturalmente representado para quem irá ler, o que defende a ideia do discurso comunicativo funcional. Concluímos, ainda, que é possível “(...) definir o trabalho da escritura do texto jornalístico como sendo uma ‘tradução’ prospectiva do fato, por excelência” (ZIPSER, 2002, p. 40). 


\section{REFERÊNCIAS BIBLIOGRÁFICAS}

BBC Reino Unido - Disponível em: 〈http://www.bbc.co.uk/news/world-africa-15389550>. Acesso em: 5 dez. 2011.

$\mathrm{BBC}$

Brasil:

Disponível

em:

<http://www.bbc.co.uk/portuguese/noticias/2011/10/111020_libia_atualiza_rc.shtml>. Acesso em: 5 dez. 2011.

BELLOS, David. Is That a Fish in your Ear? London: Penguin Books, 2011.

CARVALHO, Nelly. A unidade lexical no discurso publicitário regional. In: CONGRESSO NACIONAL DE LINGUÍSTICA E FILOLOGIA, 4, 2010, Rio de Janeiro. Anais do XIV CNLF. Rio de Janeiro, UERJ, 2010. P.419-424 Disponível em: <http://www.filologia.org.br/xiv_cnlf/tomo_1/419-424.pdf>. Acesso em: 13 abr. 2012.

ECO, Umberto. Quase a mesma coisa. Tradução de Eliana Aguiar. Rio de Janeiro: Record, 2007.

MARTINS, Ana Paula Pereira. Funcionalismo linguístico: um breve percurso histórico da Europa aos Estados Unidos. Revista Domínios de Lingu@gem, São Paulo, v. 3, n. 2, p. 1835, 2009.

NICOLOSO, Silvana. Uma investigação sobre marcas de gênero na interpretação de língua de sinais brasileira. Dissertação (Pós-Graduação em Estudos da Tradução), Universidade Federal de Santa Catarina, Florianópolis, 2010.

NORD, Christiane. Text analysis in translation: theory, methodology, and didactic application of a model for translation-Oriented text analysis. Amsterdam: Atlanta, 1991.

PINHO, J.B. Jornalismo na Internet: Planejamento e produção da informação on-line. São Paulo: Summus, 2003.

POLCHLOPEK, Silvana Ayub. A interface tradução-jornalismo: um estudo de condicionantes culturais e verbos auxiliares modais em textos comparáveis das revistas Veja e Time. Dissertação (Pós-Graduação em Estudos da Tradução), Universidade Federal de Santa Catarina, Florianópolis, 2011.

ROMANELLI, Sérgio. A gênese de um processo tradutório: Os manuscritos de Rina Sara Virgillito. Tese (Departamento de Pós-Graduação em Letras e Linguística da Faculdade de Letras), Universidade Federal da Bahia, Salvador, 2006.

VENUTI, Lawrence. Escândalos da tradução. Tradução de Laureano Pelegrin, Lucinéia Marcelino Villela, Marileide Dias Esqueda e Valéria Biondo. Bauru: EDUSC, 2002.

ZIPSER, Meta Elisabeth. Do fato à reportagem: as diferenças de enfoque e a tradução como representação cultural. Tese (Departamento de Letras Modernas da Faculdade de Filosofia, Letras e Ciências Humanas), Universidade de São Paulo, São Paulo, 2002.

Transcrição dos textos

\begin{tabular}{|l|l|}
\hline \multicolumn{1}{|c|}{ BBC BRASIL } & \multicolumn{1}{|c|}{ BBC UK } \\
\hline "Governo de transição anuncia morte de Khadafi” & Libya's Col Muammar Gaddafi killed, says NTC \\
Atualizado em 20 de outubro, 2011 - 15:31 & $\begin{array}{l}\text { 20 October 2011 Last updated at 21:02 GMT } \\
\text { Libya's ex-leader Col Muammar Gaddafi has } \\
\text { (Brasília) 17:31 GMT }\end{array}$ \\
$\begin{array}{l}\text { O ex-líder líbio Muamar Khadafi foi mortod after an assault on his birthplace of } \\
\text { durante um aque à sua cidade natal, Sirte, } \\
\text { segundo o Conselho Nacional de Transição }\end{array}$ & $\begin{array}{l}\text { Sirte, officials say. } \\
\text { Acting Prime Minister Mahmoud Jibril }\end{array}$ \\
\hline
\end{tabular}


(CNT), que governa o país.

Nesta quinta-feira, horas depois do anúncio de que Khadafi teria sido capturado e levado a Misrata, o primeiro-ministro líbio Mahmoud Jibril confirmou sua morte para jornalistas.

Em uma coletiva de imprensa na capital, Trípoli, Jibril disse que é o momento de dar início a uma Líbia nova e unida.

Khadafi estava foragido desde agosto, quando rebeldes entraram na capital Trípoli e puseram fim ao seu regime de 42 anos - o mais longevo da África, e um dos mais longos do Oriente Médio.

O governo interino pretende anunciar a Líbia "liberada" antes de indicar quais serão os próximos passos em direção às eleições democráticas no país.

$\mathrm{O}$ primeiro-ministro disse que as forças do CNT ainda estão em busca de Saif al-Islam, o filho mais conhecido do coronel Khadafi, que deixou Sirte em um comboio antes da tomada da cidade.

"Confirmação"

"Nós esperamos por esse momento durante muito tempo. Muamar Khadafi foi morto", disse Mahmoud Jibril em uma coletiva de imprensa oficial, após um dia de relatos contraditórios e rumores.

Líderes de diversos países comemoraram a notícia, pedindo que o CNT mantenha sua promessa de realizar reformas no país.

O primeiro-ministro britânico David Cameron, que teve um papel de liderança na intervenção da Otan na Líbia, disse que este é "um dia para lembrar de todas as vítimas do coronel Khadafi". O secretário-geral da ONU, Ban Ki-moon, disse que é um momento "histórico", mas alertou que "o caminho à frente da Líbia e de seu povo será difícil e cheio de desafios".

A morte de Khadafi ocorreu após semanas de combate acirrado em Sirte - um dos últimos bastiões de resistência na Líbia.

A Líbia é o terceiro país árabe, após Tunísia e Egito, a ter seu regime derrubado durante a onda de levantes conhecida como Primavera Árabe. O Tribunal Penal Internacional queria julgar o líder líbio deposto por acusações de crimes contra a humanidade.

"Imagens"

Há poucos detalhes da operação que teria resultado na morte de Khadafi. A Otan (Aliança Militar Ocidental) afirmou que bombardeou dois veículos com forças leais ao líder deposto na manhã desta quinta-feira, perto de Sirte, mas não ficou claro se o bombardeio matou o coronel.

Chegaram a circular informações de que Khadafi teria sido capturado com vida. Logo em seguida, entretanto, a TV árabe Al-Jazeera exibiu imagens do que dizia ser o corpo de Khadafi.

Outro vídeo, com imagens granuladas, que circulava entre combatentes do CNT, mostrava o announced the death, and later said the colonel had been killed in a crossfire between Gaddafi loyalists and fighters from the transitional authorities.

He confirmed that Col Gaddafi had been taken alive, but died of bullet wounds minutes before reaching hospital.

Video footage suggests he was also dragged through the streets.

It is unclear from the footage, broadcast by alJazeera $T V$, whether he was alive or dead at the time.

US President Barack Obama said it was a "momentous day" for Libya, now that tyranny had fallen.

He said the country had a "long and winding road towards full democracy", but the US and other countries would stand behind Tripoli.

Col Gaddafi was toppled from power in August after 42 years in charge of the country.

"Golden gun"

He was fighting his last stand in Sirte alongside two of his sons, Mutassim and Saif al-Islam, according to reports.

Acting Justice Minister Mohammad al-Alagi told the AP news agency Saif al-Islam had been captured and taken to hospital with a leg wound.

A corpse that officials identified as that of Mutassim has been laid out in a house in the city of Misrata, where locals have been queuing to take pictures.

The body of Col Gaddafi has also reportedly been taken to Misrata.

Nato, which has been running a bombing campaign in Libya for months, said it had carried out an air strike earlier on Thursday.

French Defence Minister Gerard Longuet said French jets had fired warning shots to halt a convoy carrying Col Gaddafi as it tried to flee Sirte.

He said Libyan fighters had then descended and taken the colonel.

Proof of Col Gaddafi's fate came in grainy pieces of video, first circulated among fighters, and then broadcast by international news channels.

The first images showed a bloodied figure presumed to be Col Gaddafi.

Later, video emerged of the colonel being bundled on to the back of a pick-up truck after being captured alive.

None of the video footage has been independently verified.

$\mathrm{Mr}$ Jibril, number two in the National Transitional Council (NTC), held a news conference in Tripoli to confirm the colonel's death.

"We have been waiting for this moment for a long time. Muammar Gaddafi has been killed," he said. Later, he told journalists that a "forensic report" 
que seria o cadáver de Khadafi.

As imagens mostram vários combatentes comemorando, com gritos de júbilo, ao redor de um corpo vestido com uma roupa cáqui semelhante a vestes usadas pelo ex-líder líbio. O cadáver tem o rosto manchado de sangue, e uma aparente ferida de bala do lado da cabeça.

Um combatente do CNT disse à BBC que encontrou Khadafi "escondido em um buraco em Sirte", e que ele teria implorado para não ser morto a tiros. O combatente mostrou aos jornalistas da BBC uma pistola dourada, que segundo ele teria sido tomada de Khadafi.

Canais de TV árabes também mostraram imagens de tropas cercando duas grandes tubulações, onde, segundo repórteres, Khadafi teria sido encontrado. had concluded that the colonel had died from bullet wounds after he had been captured and driven away.

"When the car was moving it was caught in crossfire between the revolutionaries and Gaddafi forces in which he was hit by a bullet in the head," said Mr Jibril, quoting from the report.

"The forensic doctor could not tell if it came from the revolutionaries or from Gaddafi's forces."

Earlier, some NTC fighters gave a different account of the colonel's death, saying he had been shot when he tried to escape.

One NTC fighter told the BBC that he found Col Gaddafi hiding in a hole, and the former leader had begged him not to shoot.

The fighter showed reporters a golden pistol he said he had taken from Col Gaddafi.

Arabic TV channels showed images of troops surrounding two large drainage pipes where the reporters said Col Gaddafi was found.

"Full of challenges"

Libyans gathered in towns and cities across the country to celebrate the reports of the colonel's death.

Groups of young men fired guns in the air, and drivers honked horns in celebration.

His death came after weeks of fierce fighting for Sirte, one of the last remaining pockets of resistance.

World leaders urged the NTC to carry through its promise to reform the country.

UK Prime Minister David Cameron, who had taken a leading role in Nato's intervention, said it was "a day to remember all of Col Gaddafi's victims".

UN Secretary General Ban Ki-moon called it a "historic" moment, but warned: "The road ahead for Libya and its people will be difficult and full of challenges."

Officials said the NTC intended to announce the "liberation of the country" in the coming days, allowing them to begin pushing through democratic reforms that will lead to elections.

\footnotetext{
1 “A tradução está em toda parte" (tradução nossa).

${ }^{2}$ Proferida em sua palestra "The Ubiquity (?) of Translation in our Contemporary Society, or: The Frameworks of Translation Discourse" no IV Seminário de Pesquisas em Andamento da PGET (Programa de PósGraduação em Estudos da Tradução), no dia 25 de novembro de 2011.

${ }^{3}$ GMT - Greenwich Mean Time (Hora Média de Greeenwich)

${ }^{4}$ NTC - National Transitional Council.

${ }^{5}$ Tradução da sigla NTC para o português: CNT - Conselho Nacional de Transição.
} 